\title{
UCRL-CONF-222524
}

LAW RENCE LIVERMORE N A TIO N A L LABORATORY

\section{A Simple HCCI Engine Model for Control}

N. Killingsworth, S. Aceves, D. Flowers, M. Krstic

June 30, 2006

IEEE International Conference on Control Applications Munich, Germany

October 4, 2006 through October 6, 2006 
This document was prepared as an account of work sponsored by an agency of the United States Government. Neither the United States Government nor the University of California nor any of their employees, makes any warranty, express or implied, or assumes any legal liability or responsibility for the accuracy, completeness, or usefulness of any information, apparatus, product, or process disclosed, or represents that its use would not infringe privately owned rights. Reference herein to any specific commercial product, process, or service by trade name, trademark, manufacturer, or otherwise, does not necessarily constitute or imply its endorsement, recommendation, or favoring by the United States Government or the University of California. The views and opinions of authors expressed herein do not necessarily state or reflect those of the United States Government or the University of California, and shall not be used for advertising or product endorsement purposes. 


\title{
A Simple HCCI Engine Model for Control
}

\author{
Nick J. Killingsworth ${ }^{\dagger}$, Salvador M. Aceves ${ }^{\ddagger}$, Daniel L. Flowers ${ }^{\ddagger}$, and Miroslav Krstić ${ }^{\dagger}$
}

\begin{abstract}
The homogenous charge compression ignition (HCCI) engine is an attractive technology because of its high efficiency and low emissions. However, HCCI lacks a direct combustion trigger making control of combustion timing challenging, especially during transients. To aid in HCCI engine control we present a simple model of the HCCI combustion process valid over a range of intake pressures, intake temperatures, equivalence ratios, and engine speeds. The model provides an estimate of the combustion timing on a cycleby-cycle basis. An ignition threshold, which is a function of the in-cylinder motored temperature and pressure is used to predict start of combustion. This model allows the synthesis of nonlinear control laws, which can be utilized for control of an HCCI engine during transients.
\end{abstract}

\section{INTRODUCTION}

With ever increasing pressure to reduce emissions, the need for new low polluting engine technology has never been greater. Consequently, the homogenous charge compression ignition (HCCI) engine, with its high efficiency and low particulate and NOx emissions, is a prime candidate. These benefits are a result of the ignition process; HCCI engines take advantage of a lean homogenous mixture of combustion gases that undergo autoignition during compression allowing these engines to operate with diesel-like compression ratios, giving high efficiency and low peak combustion temperatures, and reducing NOx emissions [1]. However, controlling HCCI engines is difficult because of instability of the autoignition process. Thus, developing stable and robust methods of control is paramount to achieving the potential of HCCI engines.

Model-based control requires the generation of $\mathrm{HCCI}$ engine models either from first principles or through system identification. Fully characterizing the many complex processes that occur in HCCI engines is a nearly impossible task. Moreover, the goal of this work is to provide a model that can be used to derive control laws, thus, we are only concerned with those subsystems that affect the behaviors we would like to control. Therefore, it is desirable to develop a simple model of the HCCI engine that allows us to extract the main system dynamics.

The dynamics of HCCI combustion can be modeled using either a mean value model (MVM) or discrete event model (DEM). A MVM is continuous and depicts only the average behavior of an engine. On the other hand, in a DEM all engine events correspond to the actual points in the cycle in which they occur, characterizing the reciprocating nature

$\dagger$ Department of Mechanical and Aerospace Engineering University of California, San Diego La Jolla, CA 92093-0411, U.S.A.

$\ddagger$ Lawrence Livermore National Laboratory Livermore, CA 94551 of the engine cycle. Furthermore, time is the independent variable in a MVM whereas the crankshaft angle is the independent variable for a DEM.

Several HCCI control-oriented models have been developed and most are DEM. A model including the effects of residuals induced by variable valve actuation is derived in [2]. The authors find that modeling ignition of the propaneair mixture using an integrated Arrhenius rate expression provides better results than using a temperature threshold or knock integral. The interaction within the intake and exhaust manifolds between cylinders in a multi-cylinder engine is addressed in [3], a knock integral is used to capture ignition in this work. The two stage ignition inherent in diesel fuel combustion is explicitly characterized in [4]. The initiation of the first stage is modeled using an integrated Arrhenius rate expression and the second stage by a temperature threshold that is a function of EGR and the air to fuel ratio (AFR). An HCCI engine running on ethanol fuel is modeled in [5] using a two-step reaction mechanism. In [6] a model utilizing a shell model for hydrocarbon fuels containing five species and eight reactions is compared to ignition modeled using an integrated Arrhenius rate threshold and experimental results.

Mean value models are more typical in spark ignited and diesel control-oriented models. In [7] a MVM for HCCI is considered. The model has eight states, including an exhaust gas recirculation valve and exhaust rebreathing lift. A set of algebraic equations is used to relate the in-cylinder conditions at intake valve close to the conditions at exhaust valve close. A similar cycle-by-cycle model was developed in [8] for an HCCI engine with variable valve actuation, except this model does not include flow to and from the exhaust and intake manifolds and assumes constant combustion phasing. This model is expanded in [9], where combustion phasing is accounted for using an integrated Arrhenius rate expression. Furthermore, this model provides an expression that relates the current cycle's peak pressure and combustion phasing to the inlet conditions and the previous cycle.

Although these DEMs and MVMs have made great strides in simplifying all the complex physics that take place in an HCCI engine, they are still rather complicated, making it either impossible to derive control laws or the resulting control laws are too computationally intensive for real-time implementation. There has been success linearizing some of these HCCI engine models to obtain models that are tractable for the generation of control laws [8], [10], [11]. However, these linearized models are only valid around the operating point where they are linearized. The use of a nonlinear model would yield a control law valid over a large operating range, 
making control during transients a possibility. The goal of this work is to present a model that is simple enough to allow the synthesis of nonlinear control laws, yet still captures all the main features of HCCI engine processes.

In the following section we generate an ignition line from a zero-dimensional model of HCCI combustion with detailed chemistry, where the ignition line is used to model autoignition. Subsequently, we layout all the equations that describe the compression, ignition, heat release, expansion and exhaust blowdown within the cylinder during an engine cycle. The model is then compared to the zero-dimensional model. Finally, the developed equations are combined to create a state-space model. The end result is a cycle-by-cycle model of an HCCI engine.

\section{IGNITION CORRELATION}

The key to HCCI operation is the autoignition process, synonymously this is the most crucial aspect of an HCCI model. Autoignition is controlled by chemical kinetics and is thus a complex phenomenon. The use of a detailed chemical mechanism requires the solution of hundreds of differential equations, which is computationally intensive. Often simpler modeling schemes are used, such as a global integrated Arrhenius rate equation. This method defines combustion as the point at which the integral of a function of in-cylinder temperature, pressure, and concentration of specific species reaches some critical value [12]. The integrated Arrhenius equation has been used successfully, but requires solving for the upper limit of the integral.

We propose a simpler solution to modeling autoignition, that is to correlate ignition to the point when a threshold, which is a function of in-cylinder temperature $T_{c y l}$ and pressure $p_{c y l}$, is exceeded. It was found in [13] that a $\log \left(p_{c y l}\right)$ versus $\log \left(T_{c y l}\right)$ map can be used to visualize ignition and that for many fuels, ignition falls on a line within this map. We are interested in fueling the HCCI engine with natural gas and found that for this fuel the ignition line is more linear in $p_{c y l}$ versus $T_{c y l}$ space rather than $\log \left(p_{c y l}\right)$ versus $\log \left(T_{c y l}\right)$ space.

In this section we will outline the generation of a map and the use of this map to determine an ignition line. To generate the map we use a zero-dimensional (0-D) model of HCCI combustion during the closed portion of the engine cycle, utilizing detailed chemical kinetics. Additionally, heat transfer is included using Woschni's correlation [14]. The 0 -D model treats the in-cylinder gas mixture as perfectly homogenous, such that all thermodynamic properties, temperature, pressure, and species concentration are equivalent and independent of location within the cylinder. This type of model only takes into account the bulk gas in the middle of the engine cylinder and does not account for the volume of gas lying within crevices of the engine. Neglecting the gas within the crevices causes an under-prediction of unburned hydrocarbons, thus this type of model is not useful for the prediction of $\mathrm{CO}$ or unburned hydrocarbons. Nevertheless, 0$\mathrm{D}$ models have been found to provide a good estimate of the start of combustion, [1], with minimal computational time.
The 0-D model is run with a chemical mechanism that includes species up to C4 chemistry [15] and the chemical kinetics are solved using Cantera [16]. The natural gas composition used for the simulations is given in the upper half of Table I. The simulations are run for all combinations of the conditions listed in the lower half of Table I, disregarding simulations in which CA50 is outside the range of $[-5,10]$ crank angle degrees (CAD) after top dead center (TDC). Additionally, the runs at 1300 RPM include $p_{\text {intake }}=$ $[0.9,1.1,1.2] \mathrm{atm}$.

TABLE I

SIMULATION CONDITIONS

\begin{tabular}{|ccccccccc|}
\hline Fuel Blend & $\mathrm{CH}_{4}$ & $\mathrm{C}_{2} \mathrm{H}_{6}$ & $\mathrm{C}_{3} \mathrm{H}_{8}$ & $\mathrm{C}_{4} \mathrm{H}_{10}$ & & & & \\
mol \% & 94 & 4 & 1 & 1 & & & & \\
\hline RPM & 1300 & 1500 & 1800 & 2100 & & & & \\
$p_{\text {intake }}^{\text {atm }}$ & 1 & 1.5 & 2 & 2.5 & 3 & 3.5 & 4 & \\
$T_{\text {intake }} \mathrm{K}$ & 410 & 420 & 430 & 440 & 450 & 460 & 470 & 480 \\
$\phi$ & 0.25 & 0.3 & 0.35 & 0.4 & 0.45 & & & \\
\hline
\end{tabular}

The engine parameters for the simulations correspond to an experimental HCCI engine located at Lawrence Livermore National Laboratory that is based on a Caterpillar 3406 [17] and are given in Table II. This engine has a hot and cold manifold similar to the schematic in Fig. 1 allowing individual control of the intake charge temperature for each cylinder.

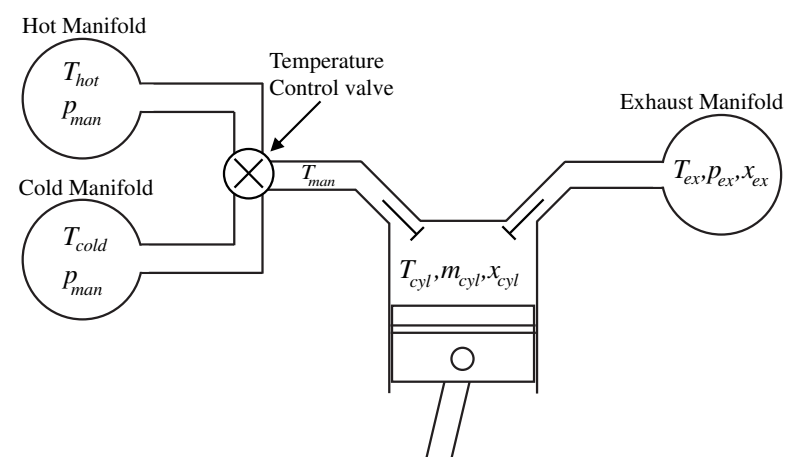

Fig. 1. Schematic of engine. The intake charge temperature is controlled using a valve to regulate the amount of intake charge that comes from the hot and cold manifolds.

TABLE II

Engine And Model Parameters

\begin{tabular}{|ccc|}
\hline Parameter & Definition & Value (if constant) \\
\hline$a$ & crank radius & $a=L / 2$ \\
$B$ & cylinder bore & $137 \mathrm{~mm}$ \\
$l$ & connecting rod length & $330 \mathrm{~mm}$ \\
$L$ & stroke & $164 \mathrm{~mm}$ \\
$V_{c}$ & clearance volume & \\
$\eta_{c}$ & combustion efficiency & 0.9 \\
$n_{c}$ & polytropic exponent during compression & 1.335 \\
$n_{e}$ & polytropic exponent during expansion & 1.35 \\
& compression ratio & $16: 1$ \\
\hline
\end{tabular}

For each run of the 0-D model the crank angle degree in which one percent heat release occurs (CA1) is determined 
and the motored pressure and temperature is noted. Figure 2 is a plot of the motored temperature versus motored pressure divided by $p_{\text {intake }}^{n}$ at which CA1 occurs, where $n=0.8$ and was found by trial and error, normalizing the motored pressure in this manner causes the data points for a given rpm to collapse onto roughly a single line. Each data point corresponds to a simulation of the 0-D HCCI model. We choose CA1 because it is essentially the point in the cycle at which chemistry becomes important and the in-cylinder pressure and temperature begin to deviate from the motored (frozen chemistry) pressure and temperature.

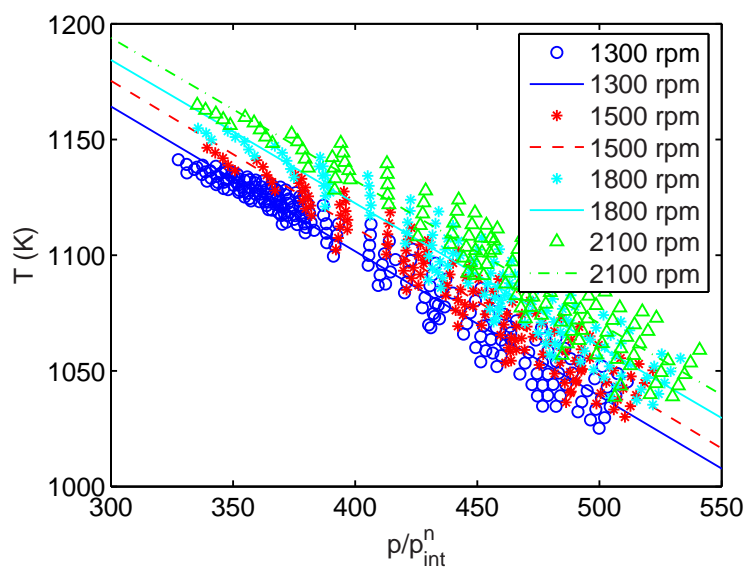

Fig. 2. Motored temperature versus normalized motored pressure at which one percent heat release occurs for multiple rpms. Ignition lines are plotted for each rpm and are least squares fit to the data.

A line is fit to the data plotted in Fig. 2 for each rpm resulting in an ignition line

$$
T_{c y l}\left(\theta_{S O C}\right)=m_{1} \frac{p_{c y l}\left(\theta_{S O C}\right)}{p_{\text {man }}^{n}}+b_{1} .
$$

The slope $m_{1}$ is almost constant with rpm resulting in parallel lines in Fig. 2 while the constant $b_{1}$ increases with rpm. This shift is expected because as the rpm increases so does the speed of the piston, whereas the chemical time scale of the reacting gas is fixed. This type of ignition model requires that $\mathrm{CA} 1$ occurs before $\mathrm{TDC}$, which is typically the case, however for engines with low heat transfer and very late combustion timing this model might not suffice.

Additionally, these simulations are used to determine a correlation for the burn duration defined as $\Delta \theta=\theta_{C A 50}-$ $\theta_{C A 1}$. Figure 3 shows the burn duration as a function of CA1 for the conditions given in Table II. We can see from this plot that the linear fit,

$$
\Delta \theta(k)=m_{2} \theta_{S O C}(k)+b_{2},
$$

does not change much with rpm, so we use a single line. There is little change in burn duration with rpm because at higher rpm ignition occurs at higher temperatures, as we can see from Fig. 2, thus the chemistry is faster and compensates for the increase in piston speed. In an actual engine the burn duration is longer than found here due to inhomogeneity of species and temperature within the cylinder.

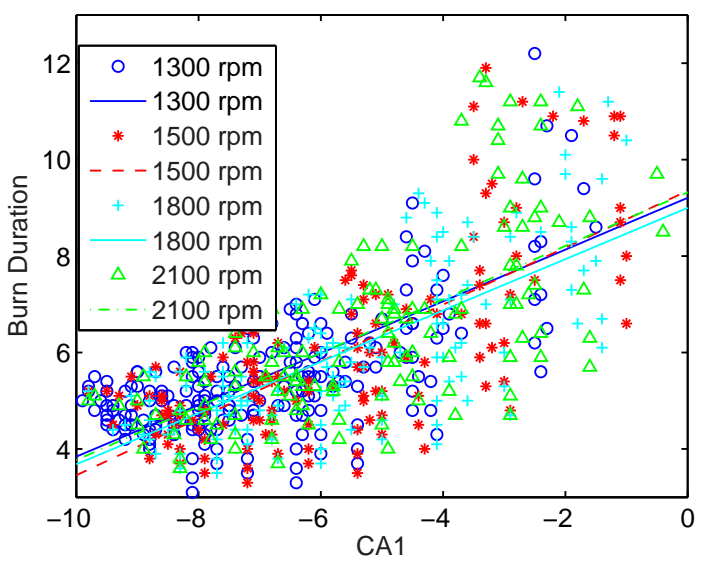

Fig. 3. Burn duration versus the crank angle at which one percent heat release occurs and linear fit of data at each rpm.

\section{HCCI CYCLE MODEL}

The model provides an estimate of the combustion timing as well as the properties of the the residual gas left in the cylinder at the end of cycle $k$. The combustion timing is the variable we are trying to control and the residual gases influences the next cycle $k+1$. The notation used in the following equations corresponds to the schematic of the engine presented in Fig. 1.

First we separate the closed portion of the cycle, which occurs from intake valve closing (IVC) to exhaust valve opening (EVO), into three phases: IVC to start of combustion (SOC), SOC to the end of combustion, and expansion of the gases to EVO. Furthermore, we will model exhaust blowdown and stroke from EVO to exhaust valve closing (EVC). The result is an algebraic relationship between the gas properties at IVC and both the combustion timing and the in-cylinder gas properties at EVC.

\section{A. Temperature Control}

We control the temperature of the intake charge and ultimately the combustion timing by regulating the portion of intake charge that comes from the hot and cold manifolds (see Fig. 1). A valve is used to control the ratio $\beta$ of mass flow from the hot and cold manifolds. Thus the overall intake manifold temperature is,

$$
T_{\text {man }}(k)=(1-\beta(k)) T_{\text {hot }}(k)+\beta(k) T_{\text {cold }}(k) .
$$

\section{B. In-cylinder Mixing}

The total mass of gas in the cylinder $m_{c y l}$ is found using the ideal gas law at IVC,

$$
m_{c y l}(k)=\frac{p_{\operatorname{man}}(k) V_{I V C}}{R T_{I V C}(k)},
$$

and is the sum of the mass of the fresh charge and the mass of residual gas trapped from the previous cycle $m_{r e s}$. The specific gas constant $R=R_{u} / M W$ is the universal gas constant 
divided by the molecular weight of the gas mixture. $m_{r e s}$ is determined using the ideal gas law at EVC,

$$
m_{r e s}(k)=\frac{p_{E V C}(k-1) V_{E V C}}{R T_{E V C}(k-1)} .
$$

The temperature of the in-cylinder gases at IVC is found from the mass weighted temperature of the fresh charge and residual gases,

$$
T_{I V C}(k)=\frac{m_{c y l}(k)-m_{r e s}(k)}{m_{c y l}(k)} T_{m a n}(k)+\frac{m_{r e s}(k)}{m_{c y l}(k)} T_{E V C}(k-1) .
$$

The air to fuel ratio in the cylinder $A F R_{c y l}$ considering the additional air contained in the residual gas is,

$$
A F R_{c y l}(k)=\left(1-x_{c y l}\right)\left(1+A F R_{\text {man }}(k)\right) \frac{m_{\text {cyl }}(k)}{m_{\text {cyl }}(k)-m_{\text {res }}(k)}-1,
$$

where $A F R_{\text {man }}$ is the air to fuel ratio of the intake charge. We keep track of the mass of the species we assume to be unreactive $m_{y, i}$ at location $y$ such as $\mathrm{N}_{2}, \mathrm{CO}_{2}$, and $\mathrm{H}_{2} \mathrm{O}$ using an inert gas fraction $x_{y}=m_{y, i} / m_{y}$, where $m_{y}$ is the total mass of gas at location $y$. The inert gas fraction in the cylinder is,

$$
x_{c y l}=x_{E V C}(k-1) \frac{m_{r e s}(k)}{m_{c y l}(k)} .
$$

\section{IVC to SOC}

The in-cylinder gases undergo a polytropic compression from IVC until SOC. Therefore during this phase the incylinder gas temperature $T_{c y l}$ and pressure $p_{c y l}$ are,

$$
\begin{aligned}
& T_{c y l}(k, \theta)=T_{I V C}(k)\left(\frac{V\left(\theta_{I V C}\right)}{V(\theta)}\right)^{n_{c}-1}, \\
& p_{c y l}(k, \theta)=p_{I V C}(k)\left(\frac{V\left(\theta_{I V C}\right)}{V(\theta)}\right)^{n_{c}},
\end{aligned}
$$

where the polytropic exponent $n_{c}$ is assumed to be constant and is chosen such that the motored pressure trace matches that of the 0-D model, which includes temperature dependent specific heats and heat transfer. The in-cylinder pressure at intake valve closing $p_{I V C}$ is assumed to be equal to the manifold pressure $p_{\operatorname{man}}$. The cylinder volume is found from the slider crank equation,

$$
V(\theta)=V_{c}+\frac{\pi B^{2}}{4}\left(l+a-a \cos \theta-\sqrt{l^{2}-(a \sin \theta)^{2}}\right),
$$

the parameters from this equation can be found in Table II.

\section{SOC to CA50}

The start of combustion occurs when the in-cylinder temperature $T_{c y l}$ and pressure $p_{c y l}$ lie on the ignition line equation (1) and $\theta_{S O C}$ is the argument of $T_{S O C}(\theta)$ when the ignition line is crossed. $T_{S O C}$ and $p_{S O C}$ are found from (9)-(10) with (11) evaluated at $\theta_{S O C}$. It is assumed that fuel reacts instantaneously at the crank angle where $50 \%$ of the heat is released (CA50). CA50 occurs $\Delta \theta$ after the start of combustion $\theta_{S O C}$ assuming that the combustion duration is found from equation (2). The in-cylinder pressure and temperature adhere to equations (9) and (10) until,

$$
\theta_{C A 50}=\theta_{S O C}+\Delta \theta
$$

at which,

$$
T_{C A 50}=T_{b c}+\Delta T
$$

where $T_{b c}$ is the in-cylinder gas temperature before combustion found from equation (9) evaluated at $\theta_{C A 50}$. The temperature rise due to combustion is,

$$
\Delta T(k)=\frac{\eta_{c} Q_{L H V}}{c_{v}} \frac{1-x_{c y l}(k)}{1+A F R_{c y l}(k)},
$$

where the combustion efficiency $\eta_{c}$ accounts for incomplete combustion and is assumed to be constant, $Q_{L H V}$ is the lower heating value of the fuel, and $c_{v}$ is the specific heat at constant volume of the in-cylinder gas. The pressure at $\theta_{C A 50}$ can be found using the ideal gas law.

\section{E. CA50 to EVO}

The gas then undergoes a polytropic expansion until the exhaust valve opens, the in-cylinder pressure and temperature at EVO are,

$$
\begin{aligned}
& T_{E V O}(k)=T_{C A 50}(k)\left(\frac{V\left(\theta_{C A 50}\right)}{V\left(\theta_{E V O}\right)}\right)^{n_{e}-1}, \\
& p_{E V O}(k)=p_{C A 50}(k)\left(\frac{V\left(\theta_{C A 50}\right)}{V\left(\theta_{E V O}\right)}\right)^{n_{e}} .
\end{aligned}
$$

\section{F. Exhaust Blowdown}

At exhaust valve closing it is assumed that the gas undergoes an adiabatic expansion from the pressure at EVO $p_{E V O}$ down to the exhaust manifold pressure and there is a drop in temperature $\Delta T_{e x}$ due to heat loss,

$$
T_{E V C}(k)=T_{E V O}(k)\left(\frac{p_{E V C}(k)}{p_{E V O}(k)}\right)^{\left(n_{e}-1\right) / n_{e}}+\Delta T_{e x} .
$$

\section{G. Residual Gas State}

The inert gas fraction of the gas in the cylinder after combustion assuming complete combustion is,

$$
x_{E V C}(k)=\left(\frac{1+A F R_{\text {stoich }}}{1+A F R_{c y l}(k)}\right)\left(1-x_{c y l}(k)\right)+x_{c y l}(k),
$$

where $A F R_{\text {stoich }}$ is stoichiometric air to fuel ratio.

\section{RESUlts AND Discussion}

The model presented in this paper is compared to the 0D model outlined in section II. Figure 4 shows the error in CA50 $e_{C A 50}=\theta_{C A 50,0 D}-\theta_{C A 50, S M}$ between the zerodimension model and the simple model presented here. Each circle is the average error in CA50 $e_{C A 50}$ for a fixed intake pressure $p_{\text {intake }}$ spanning the range of intake temperatures $T_{\text {intake }}$ and equivalence ratios $\phi$ in Table I at $1300 \mathrm{rpm}$. The error bars show the standard deviation for each fixed intake pressure.

Figure 4 shows that there is three to four degrees of bias error in CA50 between the models around atmospheric intake pressure. As the intake pressure increases the average error decreases, however the standard deviation increases. The simple model predicts CA50 early at low intake pressures and late for higher intake pressures. And in some cases for 


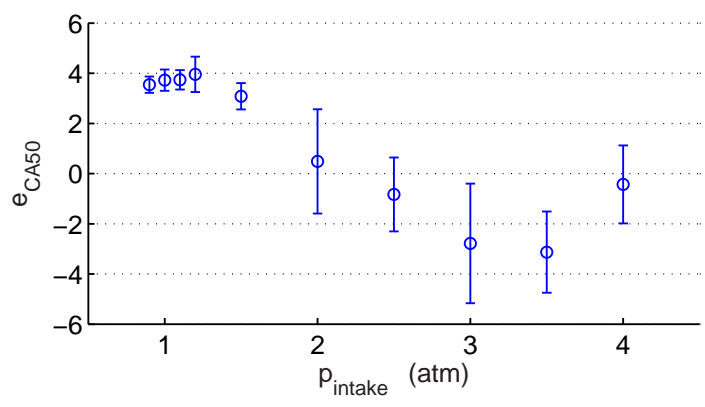

Fig. 4. Average error between CA50 predicted by the zero-dimensional model and the simple model for $1300 \mathrm{rpm}$ and various $T_{\text {intake }}$ and $\phi$ plotted versus $p_{\text {intake }}$. The error bars indicate the standard deviation.

higher rpm and intake pressures the model does not predict ignition. This discrepancy occurs because the model does not accurately predict the motored pressure over the whole range of intake pressures. The polytropic exponent during compression $n_{c}$ is picked so that the motored pressure matches that of the zero dimensional model at an intake pressure of $2.5 \mathrm{~atm}$ and an intake temperature of $435 \mathrm{~K}$. Because $n_{c}$ is fixed the simple model over predicts the motored pressure and temperature at low intake pressures and under predicts these at higher intake pressures. This error is due to two reasons, at higher intake pressures less temperature is required to ignite the mixture so the accompanying intake temperature at high pressures is typically lower, which necessitates a larger polytropic exponent $n_{c}$. Secondly, at higher intake pressures there is more mass in the cylinder while the surface area is the same so proportionally there is less heat transfer per mass of gas.

Furthermore, an increase in the standard deviation is due to using a single line to approximate the variation present in the data for the ignition line in Fig. 2 and in the correlation for the burn duration in Fig. 3. This scatter occurs in part because the ignition line (1) is not a function of the equivalence ratio. If the engine is expected to operate over a smaller range of intake pressures we anticipate that this model will provide better results. For example, naturally aspirated automobile engines typically operate at $p_{\text {intake }} \cong 1 \mathrm{~atm}$, this condition is easier to model.

To improve the performance of the model over the range of intake pressures it is possible to compensate for the errors in the motored pressure by adjusting the ignition line. By requiring the line to pass through a point corresponding to an intake pressure of $2.5 \mathrm{~atm}$ and rotating it clockwise about this point the modified ignition line will require more pressure and temperature for ignition than the original ignition line at low intake pressures and less at higher intake pressures. Figure 5 shows the modified ignition line for $1300 \mathrm{rpm}$. And Fig. 6 presents the error in CA50 when the modified ignition line is used for all rpms and conditions listed in Table I. We can see from Fig. 6 that the mean error in CA50 is closer to zero and the standard deviation is within two CAD for low intake pressures except for $p_{\text {intake }}=1.1 \mathrm{~atm}$ and well within $4 \mathrm{CAD}$ at higher intake pressures. And ignition is predicted for all cases.

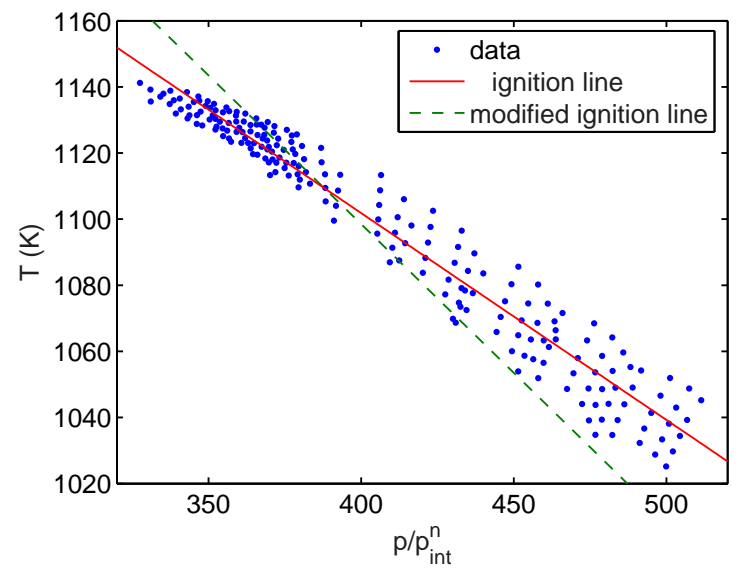

Fig. 5. Motored temperature versus normalized motored pressure at which one percent heat release occurs. Solid red is the ignition line and the dashed green line is the modified ignition line.

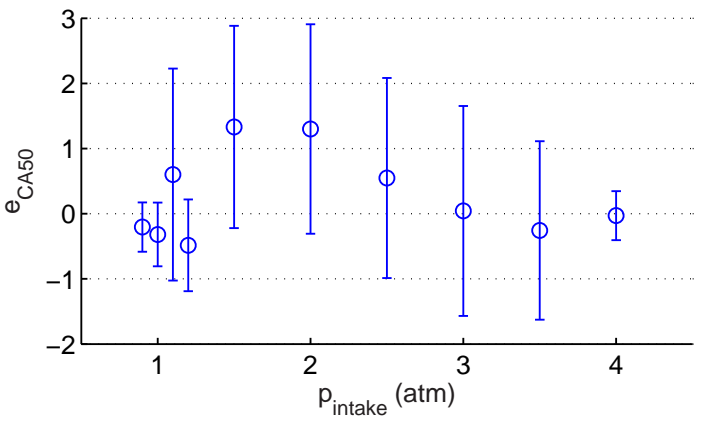

Fig. 6. Average error between CA50 predicted by the 0-D model and the simple model using the modified ignition line for various $T_{\text {intake }}, \phi$, and $\mathrm{rpm}$, plotted versus $p_{\text {intake. }}$. The error bars indicate the standard deviation.

\section{CONTROL Formulation}

Equations (1)-(18) are combined to form one relation between the conditions at IVC and EVC. It is assumed that the exhaust manifold pressure $p_{e x}$ is constant, which is close to reality except if the engine is turbocharged. Firstly, we insert (9) and (10) into (1) and arrive at,

$$
T_{I V C}(k)\left(\frac{V\left(\theta_{I V C}\right)}{V\left(\theta_{s o c}\right)}\right)^{n_{c}-1}=m_{1} p_{\text {man }}^{(1-n)}(k)\left(\frac{V\left(\theta_{I V C}\right)}{V\left(\theta_{s o c}\right)}\right)^{n_{C}}+b_{1},
$$

we then solve equation (19) for $\theta_{s o c}$

$$
\theta_{\text {soc }}=f\left(T_{I V C}(k), p_{\operatorname{man}}(k), V\left(\theta_{I V C}\right), m_{1}, b_{1}\right) .
$$

The in-cylinder temperature at the end of the cycle shown in equation (21) depends on the current value of several parameters in green and blue, and on the exhaust temperature from the past cycle $T_{E V C}(k-1)$. Where the color red is used to indicate the state, magenta the control variable, green measured disturbances, and cyan is used to indicate variables that depend on other variables. The in-cylinder temperature at IVC, 


$$
T_{E V C}(k)=\left[T_{I V C}(k)\left(\frac{V_{I V C}}{V_{C A 50}}\right)^{n_{c}-1}+\frac{c_{1}}{1+A F R_{\operatorname{man}}(k)}\left(1-\frac{c_{2}}{p_{\operatorname{man}}(k)} \frac{T_{I V C}(k)}{T_{E V C}(k-1)}\right)\right]^{\frac{1}{n_{e}}}\left(T_{I V C}(k) \frac{p_{E V C}}{p_{\operatorname{man}}(k)} \frac{V_{C A 50}}{V_{I V C}}\right)^{\frac{\left(n_{e}-1\right)}{n_{e}}}
$$

$$
T_{I V C}(k)=\frac{(1-\beta) T_{h o t}(k)+\beta T_{\text {cold }}(k)}{1-\frac{c_{2}}{p_{\operatorname{man}}(k)}\left(1-\frac{(1-\beta) T_{h o t}(k)+\beta T_{\text {cold }}(k)}{T_{E V C}(k-1)}\right)}
$$

appears in (21) multiple times. All variables in black text are assumed to be constant, specifically $c_{1}=\eta_{c} Q_{L H V} / c_{v}$ and $c_{2}=p_{E V C} V_{E V C} / V_{I V C}$.

The inert gas fraction does not appear in the control formulation of the simple model, this is because it cancels out when the equation for $A F R_{c y l}$ (7) is substituted into the equation for $\Delta T$ (14). Finally, the state-space model is,

$$
\begin{aligned}
& x=T_{E V C}, \\
& u=\beta, \\
& d=\left[\begin{array}{llll}
T_{\text {hot }} & T_{\text {cold }} & p_{\text {man }} & A F R_{\text {man }}
\end{array}\right]^{T}, \\
& y=C A 50 .
\end{aligned}
$$

We desire to regulate CA50, which can be calculated as, $C A 50(k)=\left(1+m_{2}\right) \theta_{\text {soc }}+b_{2}$.

\section{CONCLuSions}

We have presented a simple cycle-by-cycle model of an HCCI engine that relates the current cycle's combustion timing $C A 50(k)$ and in-cylinder temperature at EVC $T_{E V C}(k)$ to the past cycle's $T_{E V C}(k-1)$ and various measured parameters from the current cycle including the control variable $\beta(k)$. This model uses an ignition line derived in section II, which is a function of the motored in-cylinder pressure and temperature to predict the start of combustion. The simple model is compared to a $0-\mathrm{D}$ model of HCCI combustion including detailed chemical kinetics and it is found that the simple model predicts ignition early at lower intake pressures and late for higher intake pressure, the ignition line is modified to correct for this discrepancy. After this modification the simple model is found to agree fairly well with the 0 -D model over a range of simulation conditions. The next step is to develop control algorithms based on the state space model, which should be straight forward since the model is first-order. Additionally, this model needs to be validated against experimental data.

\section{ACKNOWLEDGMENTS}

This work was performed under the auspices of the U.S. Department of Energy by the University of California, Lawrence Livermore National Laboratory under Contract No. W-7405-Eng-48.

\section{REFERENCES}

[1] S. M. Aceves, D. L. Flowers, J. Martinez-Frias, J. R. Smith, R. Dibble, M. Au, and J. Girard, "HCCI combustion: analysis and experiments," SAE paper no. 2001-01-2077, 2001.

[2] G. M. Shaver, J. C. Gerdes, M. Roelle, P. A. Caton, and C. F Edwards, "Dynamic modeling of residual-affected homogenous charge compression ignition engines with variable valve actuation," Journal of Dynamic Systems, Measurement, and Control, vol. 127, pp. 374-381, 2005.

[3] J. S. Souder, P. Mehresh, J. K. Hedrick, and R. W. Dibble, "A multicylinder HCCI engine model for control," in Proc. ASME IMECE, IMECE2004-61966, Anaheim, CA, 2004.

[4] M. Canova, R. Garcin, S. Midlam-Mohler, Y. Guezennec, and G. Rizzoni, "A control - oriented model of combustion process in a $\mathrm{HCCI}$ diesel engine," in Proc. IEEE ACC, Portland, OR, pp. 4446-4451, 2005.

[5] F. Sun, X. Chen, D. S-K Ting, and A. Sobiesiak, "Modeling operation of HCCI engines fueled with ethanol," in Proc. IEEE ACC, Portland, OR, pp. 1003-1009, 2005.

[6] J. Bengtsson, M. Gafvert, and P. Strandh, "Modeling of HCCI engine combustion for control analysis," in Proc. IEEE CDC, Paradise Island, Bahamas, pp. 1682-1687, 2004.

[7] D. J. Rausen, A. G. Stefanopoulou, J. M. Kang, J. A. Eng, and T. W. Kuo, "A mean-value model for control of homogenous charge compression ignition (HCCI) engines," Journal of Dynamic Systems, Measurement, and Control, vol. 127, pp. 355-362, 2005.

[8] G. M. Shaver, and J. C. Gerdes, "Cycle-to-cycle control of HCCI engines," In the Proc. of the ASME International Mechanical Engineering Congress and Exposition, IMECE2003-41966, Washington, DC, 2003.

[9] G. M. Shaver, J. C. Gerdes, and M. Roelle, "Physics-based closed-loop control of phasing, peak pressure, and work output in HCCI engines utilizing variable valve actuation," in Proc. IEEE ACC, Boston, MA, pp. 150-155, 2004.

[10] C. J. Chiang, and A. G. Stefanopoulou, "Control of thermal ignition in gasoline engines," in Proc. IEEE ACC, Portland, OR, pp. 3847-3852, 2005.

[11] G. M. Shaver, M. Roelle, and J. C. Gerdes, "Decoupled control of combustion timing and work output in residual-affected HCCI engines," in Proc. IEEE ACC, Portland, OR, pp. 3871-3876, 2005.

[12] J. C. Livengood, and P. C. Wu,"Correlation of autoignition phenomena in internal combustion engines and rapid compression machine," in Proc. Fifth Int. Symp. on Combustion, pp. 347-356, 1955.

[13] S. M. Aceves, D. L. Flowers, J. Martinez-Frias, F. Espinosa-Loza, W. J. Pitz, and R. Dibble, "Fuel and additive characterization for HCCI combustion,” SAE paper no. 2003-01-1814, 2003.

[14] J. B. Heywood, Internal Combustion Engine Fundamentals, McGrawHill, 1988.

[15] H. J. Curran, National University of Ireland, Galway, Private communication, 2006.

[16] D. G. Goodwin, "An open-source, extensible software suite for CVD process simulation," in Proc. CVD XVI and EuroCVD Fourteen, Electrochemical Society, 2003, pp. 155-162.

[17] D. L. Flowers, J. Martinez-Frias, F. Espinosa-Loza, N. J. Killingsworth, S. M. Aceves, R. Dibble, M. Krstic, and A Bining, "Development and testing of a 6-cylinder HCCI engine for distributed generation," in Proc. ASME ICEF, Ottawa, Canada, 2005. 